\title{
Testing and Verification through Virtual Product Models: A survey and look ahead
}

\author{
Andrea Serester*, Gergely Hidas*, Gábor Szögi*, Péter Galambos*† \\ *Antal Bejczy Center for Intelligent Robotics, Óbuda University, Bécsi út 96/b, H-1034 Budapest, Hungary \\ $\dagger$ Institute for Computer Science and Control, Hungarian Academy of Sciences, Kende u. 13-17, H-1111 Budapest, Hungary \\ ${ }_{\ddagger}^{\ddagger}$ TÜV Rheinland InterCert Ltd., Váci út 48/A-B, H-1132 Budapest, Hungary \\ E-mail: peter.galambos@irob.uni-obuda.hu
}

\begin{abstract}
Modern engineering design and simulation software (CAD, CAM, CAE) allow for extensive use of virtual prototypes along the product and production development reducing the cost and time of physical prototyping. These software technologies in turn has also important role in testing and verification against the various regulations. This paper reviews the recent progress of virtual verification (ViVer) technology and the underlying emerging concepts with special focus on the role of certification service providers. The paper covers multiple aspects of the ViVer concept serving as a conceptual guideline for the development of virtual verification systems of the future.

Index Terms - product certification, product testing, virtual verification, virtual prototyping, computer aided engineering (CAE), virtual reality
\end{abstract}

\section{INTRODUCTION}

Direct use of computers in product development dates back to the 1960's when the ancestor of all modern CAD system called Sketcpad developed by MIT's young researcher Ivan Sutherland [1], [2]. Today, computers and extremely powerful engineering software pervade every aspects of product and production design covering the full product lifecycle. Companies like Siemens, Dassault Systéms and PTC among many others deliver advanced PLM frameworks for all industrial segments [3], [4]. Recent research activity in PLM focuses on the improvement of concurrent engineering paradigm and widening the applicable range of virtual prototyping [5], [6], [7], [8], [9] and virtual product development.

Over the mere engineering aspects of product innovation, due to the strict and complicated regulations on product compliance, testing and verification processes has a significant role in product lifecycle in terms of cost and time requirement [10], [11], [12]. In practice, every new product undergoes certification/verification, which requires the transportation of a prototype (manufactured immediately after the completion of the design process) to a suitably equipped verification laboratory. Whenever the verification procedure fails, the product is re-designed, its prototype is manufactured once again, and re-submitted for a new round of verification.

The latest engineering software technology allows for checking and optimizing products through virtual prototypes with continuously improving certainty reducing the number of physically built prototypes [13]. However, product certification requires certain standard-defined test cases that need the special knowledge of various regulations to define the test scenarios in generic engineering tools. In practice, the product development and product certification is usually separated, compliance is investigated by specialized certification companies.

Test, inspection and verification tasks are relevant to a very wide range of consumer products, hence, virtual verification has the potential to influence a large sector of world economy. Virtual design and testing is a key concept in cutting-edge $\mathrm{R} \& \mathrm{D}$, and companies are seeing a strong incentive to move in this direction by e.g., integrating the design and verification procedures into a coherent whole starting from the very beginning of product development, and by combining existing tools that support these procedures with virtualization infrastructure [14]. More specifically, the sub-area of non-destructive testing alone is estimated to generate about $€ 1.23$ billion world-wide (and $€ 370$ million within Europe), which translates into a growth rate of about $7.2 \%{ }^{1}$.

This study surveys various aspects of this evolution towards a visionary software infrastructure that integrates the testing, verification and certification functions into PLM through specific means of Virtual Reality.

The paper is structured as follows: Section II recalls the history and the motivation for model-based testing. A visionary methodology of Virual Verification is discussed in III, while section IV gives a short outlook on the ViVer aspects of safetyrelated verification of modern robotized production systems. Section V identifies the special role of test and verificationspecific engineering knowledge in use of engineering simulation software. Finally, section VI concludes the paper.

\section{EARly ADOPters: AerospaCe AND Automotive INDUSTRIES}

In the past 10 years, advances in informatics have brought about the incentive within the domain of cost-intensive industrial production to minimize the costs associated with prototype development. An important part of these incentives is to provide facilities for the internal, virtual quality assurance, testing and verification of prototypes [14], [13], [6]. The first segment in which these incentives were formulated were the

${ }^{1}$ Source: Frost \& Sullivan 2014 
aerospace and automotive industries [15], [16], [17], in which companies developed a set of quality assurance procedures which were to be observed and applied by all actors of the product supply chain. However, the implementation of all of these procedures significantly increased the costs of individual suppliers, which reduced the incentives for further co-operation. In parallel, ideas for virtualized verfication also appeared in the testing and validation of close-to-finalized product models (i.e., prototype vehicles), as a means to reduce the costs associated with the maintenance of a physical laboratory environment, along with the tools necessary to physically build prototypes. One of the more rudimentary steps in this direction involved a set of quality control guidelines which were to be met in advance before any kind of prototype would be produced. However, the first generation of such solutions still incurred considerable costs, and were therefore not available to smaller suppliers within the sector. In this case, smaller functional components (i.e., various car parts) were instead sent to specialized companies such as TÜV Rheinland for product verification.

The standards and guidelines, as well as the standard toolsets used for their implementation in complex industries (such as the automotive industry) are under constant change and improvement. The standards and guidelines used today adopt a completely different approach from those used a decade ago. Verification and quality assurance procedures have been developing in a direction where the prior measurement data and quality control data collected by the manufacturer are used directly to obtain a highly accurate estimate of the quality of the end product (this can be referred to as the family of precalculation based methods). The many examples of application domains in which virtual verification procedures are used on a daily basis and have legally binding effects include e.g., automotive crash tests, switching gears (EN 61439), etc. Not all standards allow the use of pre-calculation based methods, but standardization practices are inevitably evolving in this direction. As a result, manufacturers (as opposed to companies specializing in validation) have growing responsibilities in terms of quality assurance, and are therefore increasingly focusing on quality management and risk assessment procedures that can be integrated into the manufacturing process from the early stages of product design.

\section{INTEGRATED ONLINE ECOSYSTEM FOR AGILE DESIGN-VERIFICATION LOOP}

The economic impact can be increased through an emerging paradigm that combines virtual product design and testing based on cloud-based online services [18], [19], which is currently and dominantly based on offline engineering toolsets. This integration, which will occur both at the level of product development and at the level of verification/certification standards can enhance the entire chain of R\&D\&I extended with verification $(R \& D \& I \& V)$ behind the entire PLM workflow. This will in turn radically improve the capacity of various branches of industry to flexibly develop new products, and at the same time it will decrease the costs and time associated with development and verification procedures, as well as reduce environmental risks by helping to reduce material and transportation costs in the design and prototyping phases.

This recently forming approach is often referred to as Virtual Verification, thus this terminology is used along this study. The rest of this section discusses the practical aspects of Virtual Verification on a usecase level. Figure 1 briefly illustrates the functions that should be covered in such a service ecosystem supporting the agile product development.

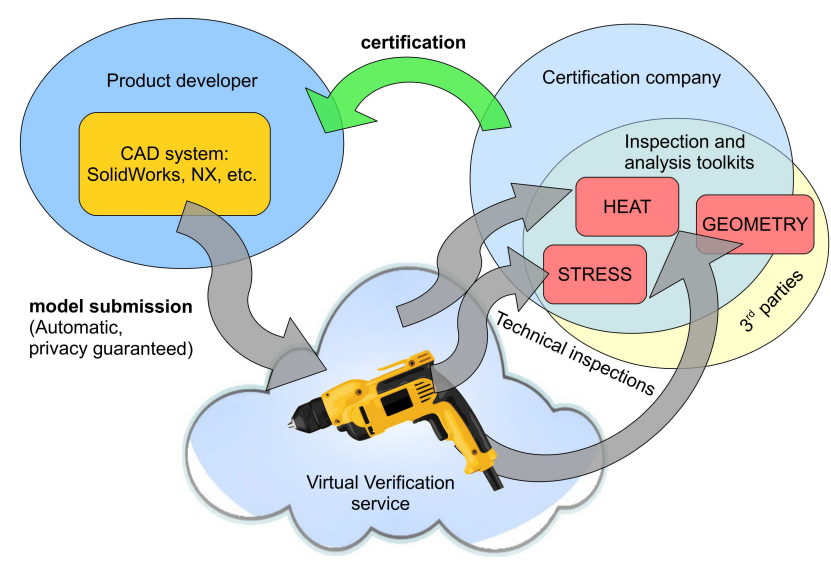

Fig. 1. Conceptual overview of the Virtual Verification process illustrating the relationship of the product developer, the certification company and the 3rdparty entities providing various analytic tools built into a commercial cloud ecosystem.

The essence of the new paradigm is to allow for the parallel execution of tasks relevant to the design, manufacturing and certification/verification of products - starting from the level of formulation of conceptual ideas all the way to practical realization - based on an Internet based 3D virtual collaboration platform such as VirCA (Virtual Collaboration Arena) [20], [21], [22]. The use of 3D virtual collaboration as an underlying technological framework yields several benefits:

1) Leads to an increase in manufacturing throughput, while reducing costs and environmental risks.

2) Enables the engineering design process to continuously follow the results of verification stages, thus minimizing risks of encountering unanticipated pitfalls which would otherwise result in a waste of considerable time and resources.

3) Eventually pave the way for the deployment of almost entirely automated virtual verification procedures.

The appearance of the new integrated tight-loop software services is timely and in line with current trends in engineering and manufacturing [23], [24], [25]. Software capable of simulating various physical phenomena (e.g., stress, heat transfer, acoustics, hydrodynamics, dynamics, durability etc. ) are in widespread use in engineering design, and the design process itself is primarily executed using 3D design systems. However, in contrast to this high degree of automation in engineering design, the technology behind verification procedures is not 
nearly as technology-driven (it is mostly manually performed on real prototypes). Hence, the goal of this is to introduce the appropriate virtual toolset (based on the existing simulation engines) into the context of product test and verification. The integration of current intelligent systems with smart virtual spaces will further allow for the verification process to be managed in networked settings. In summary, the paradigm behind this approach will allow for the enhancement of verification procedures, thus offering a radically new aspect to product management in a way that is in line with the best engineering practices.

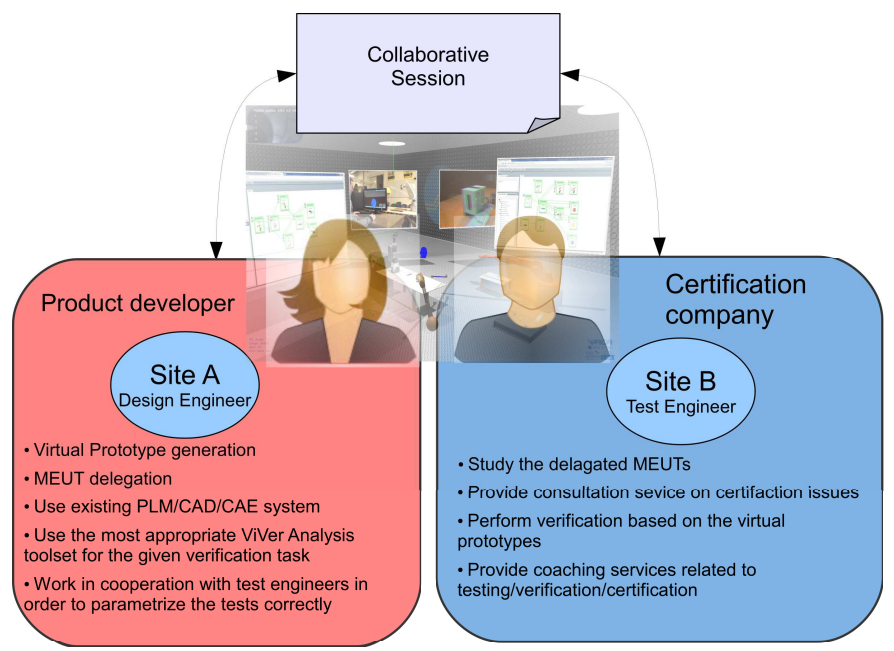

Fig. 2. Activity of different stakeholders in a collaborative verification session.

\section{VERIFICATION OF THE PRODUCTION PROCESS}

Not only the product itself but the production process also very important concerning safety issues. Standards e.g., BS EN 292:1991, BS EN 294:1992, BS EN 1050:1997, BS EN 60204-1:2006+A1:2009 regulates the machinery safety and occupational safety. Safety requirements for industrial robots and robotic devices are covered by the BS EN ISO 102181:2011 standard.

These matured regulations are well applicable for conventional machinery and production lines, however, the newest generation of collaborative industrial robots require radically new concepts. Real-life scenarios considering different means of collaboration between human and robots are under investigation for the purpose of standardization but there is no published draft up till today. This topic has been touched by the scientific community and several influential works have been published (e.g., [26], [27], [28], [29], [30]).

Main goal of the standardization process is to introduce a set of mandatory safety functions that prevent the injury of the human co-working with collaborating industrial robots. Validation of these safety functions renders new challenges for the testing and certification companies familiar with the former generation of safety standards. Realtime simulations in merged physical and virtual environments give a promising toolset along the conceptual framework of virtual verification.
The latest Virtual Reality (VR) and Augmented Reality (AR) devices and recently spreading spatial recognition technologies together allows for testing scenarios where some components of the system (e.g., workpiece, robot, gripper) are represented only virtually while other elements and the safety control logic are real. This concept is discussed in [31] and [20] considering virtual commissioning of production systems.

\section{INTERDISCIPLINARY UNDERPINNINGS OF VIRTUAL VERIFICATION}

Model-based product testing in general requires several types of resources in terms of digital description of the products and computational methods. Execution of a test case also needs the precise parametrization of the concrete investigation. Parametrization usually means the definition of initial and/or boundary conditions with additional constraints to mathematically describe a test case. In conclusion, parametrization makes the connection between the product model and the available mathematical methods so that the input data and the simulation process together lead to an interpretable result in terms of pass or fail a compliance check.

It is also noteworthy that the parametrization of an engineering simulation requires special skill in case of product testing purpose: While a product developer sets up a simulation in order to optimize a product concerning cost and quality aspects, a test engineer interprets a large set of regulations and formalize a synthetic simulation that helps to judge the product's compliance for given standards.

Applying the currently available simulation software, virtual test synthesis are viable in a wide range of engineering fields. Table I collects some relevant academic disciplines and the corresponding investigations and software categories. These fields are considered as main direction where the Virtual Verification concept can spread in the upcoming years.

\section{CONCLUSION}

Based on the previously analysed situation the following challenges need to be overcome:

- Production line and/or production machines and verification procedures must be adapted to and integrated into the virtual verification process

- Potentially hostile and aggressive production environments must be adapted to, and consequences for calibration, accuracy, aging, drift, etc. must be taken into consideration

- In-line test, inspection and verification procedures have to be developed to a level where they can be accepted as an alternative to end-of-line test, inspection and verification procedures for certification purposes

- Tests have to be formulated at the levels of product, system and subsystem integration

The predictable global impact of virtual verification technologies can be summarized in the following points:

- The Virtual testing and verification service will decrease the time-to-market duration. This only one effect has huge 
TABLE I

A POSSIBLE CATEGORIZATION OF SCIENTIFIC DISCIPLINES CONCERNING THE APPLICABILITY WITHIN THE VIVER CONCEPT

\begin{tabular}{|c|c|c|}
\hline Scientific/technical discipline & Observable features / phenomena & Related class of engineering software \\
\hline Geometry & $\begin{array}{l}\text { Length/distance } \\
\text { Curvature } \\
\text { Angle } \\
\text { Area/surface } \\
\text { Volume } \\
\end{array}$ & $\begin{array}{l}\text { CAD } \\
\text { CAM }\end{array}$ \\
\hline Mechanics & $\begin{array}{l}\text { Balance } \\
\text { Motion } \\
\text { Stress } \\
\text { Deformations } \\
\text { Vibrations } \\
\text { Acoustics }\end{array}$ & $\begin{array}{l}\text { Multibody dynamics } \\
\text { Rigid body simulations } \\
\text { Finite Element Analysis (FEA) } \\
\text { CTR and SPPS-based acoustic software }\end{array}$ \\
\hline Optics & $\begin{array}{l}\text { Color } \\
\text { Luminescence } \\
\text { Contrast } \\
\text { Reflections } \\
\text { Refractions } \\
\text { Diffraction } \\
\text { Interference }\end{array}$ & $\begin{array}{l}\text { Geometric optics / Ray optics simulators } \\
\text { Wave optics simulators }\end{array}$ \\
\hline Electrotechnics & $\begin{array}{l}\text { Voltage } \\
\text { Current } \\
\end{array}$ & Circuit simulation software \\
\hline Electromagnetism & $\begin{array}{l}\text { Electromagnetic emission } \\
\text { Wave propagation }\end{array}$ & Simulators based on computational electromagnetics \\
\hline Transport processes (in general sense) & $\begin{array}{l}\text { Heat and mass transfer } \\
\text { Conduction and diffusion } \\
\text { Radiative heat transfer } \\
\text { Conductive transport }\end{array}$ & Finite Volume Analysis (FVA) \\
\hline Chemistry & $\begin{array}{l}\text { Chemical reactions } \\
\text { Solvation } \\
\text { Corrosion } \\
\text { Electrodeposition }\end{array}$ & Chemical process simulators \\
\hline Human Factors & $\begin{array}{l}\text { Ergonomic / Anthropometric measures } \\
\text { Psychologycal effects }\end{array}$ & $\begin{array}{l}\text { Ergonomics databases } \\
\text { Ergonomics analysis software }\end{array}$ \\
\hline
\end{tabular}

and several further effects and one of the most important development factors of the industry.

- The use of 3D and simulation software as well as the development of these software will increase.

- The testing and verification based on digital models will be introduced many additional areas of the standardisation. The special procedures of the virtual testing and verification should be developed by international standardization bodies together with industrial partners. This will also enhance the distribution of the new technology.

- Legislation shall introduce new aspects: the concept of purely virtually verified products together with the aspects of product liability. This process has started however the new technology on a new area will boost the legislative change that will make further development in the introduction of new technologies of the early stage of product development.

Advanced products increase the complexity of test \& inspection tasks, which extend to the validation of tools, the calibration and control of manufacturing processes. The professional test and verification laboratories has not yet made Virtual Verification to be an everyday practice, but smart and adaptive verification has already started to be integrated into every phase of product design and manufacturing.

\section{ACKNOWLEDGMENT}

The research was supported by the Ministry of Human Capacities of Hungary.

\section{REFERENCES}

[1] I. Sutherland, "Sketchpad-a graphical man-machine interface," $P h D$ dissertationMIT, Cambridge, MA, 1963.

[2] D. T. Ross and J. E. Rodriguez, "Theoretical Foundations for the Computer-aided Design System," in Proceedings of the May 21-23, 1963, Spring Joint Computer Conference, ser. AFIPS '63 (Spring). New York, NY, USA: ACM, 1963, pp. 305-322.

[3] F. Ameri and D. Dutta, "Product Lifecycle Management: Closing the Knowledge Loops," Computer-Aided Design and Applications, vol. 2, no. 5, pp. 577-590, Jan. 2005.

[4] J. Stark, "Product Lifecycle Management," in Product Lifecycle Management, ser. Decision Engineering. Springer London, 2011, pp. 1-16.

[5] B. Liu, R. I. Campbell, and E. Pei, "Real-time integration of prototypes in the product development process," Assembly Automation, vol. 33, no. 1, pp. 22-28, Feb. 2013.

[6] M. Bordegoni and F. Ferrise, "Designing interaction with consumer products in a multisensory virtual reality environment," Virtual and Physical Prototyping, vol. 8, no. 1, pp. 51-64, 2013.

[7] B. H. Li, X. Chai, X. Yan, and B. Hou, Eds., Multi-Disciplinary Virtual Prototype Modeling and Simulation Theory and Application. Nova Science Pub Inc, Nov. 2012.

[8] K. Tahera, C. Earl, and E. Claudia, "Integrating virtual and physical testing to accelerate the engineering product development process," $I n$ ternational Journal of Information Technology and Management, vol. 13, no. 2-3, pp. 154-175, Jan. 2014.

[9] J. Huang, S. Ong, and A. Nee, "Real-time finite element structural analysis in augmented reality," Advances in Engineering Software, vol. 87 , no. 0 , pp. $43-56,2015$. 
[10] P. Maropoulos and D. Ceglarek, "Design verification and validation in product lifecycle," $\{$ CIRP $\}$ Annals - Manufacturing Technology, vol. 59 , no. 2, pp. $740-759,2010$.

[11] K. Tahera, C. Earl, and C. Eckert, "The role of testing in the engineering product development process," Karlsruhe, Germany, May 2012.

[12] K. Tahera, C. Eckert, and C. Earl, "Highlighting the importance of testing in the product development process," in 20th International Conference on Engineering Design, ICED15., July 2015.

[13] F. Ferrise, M. Bordegoni, and U. Cugini, "Interactive Virtual Prototypes for Testing the Interaction with new Products," Computer-Aided Design and Applications, vol. 10, no. 3, pp. 515-525, 2013.

[14] D. Talaba and A. Amditis, Eds., Product Engineering: Tools and Methods Based on Virtual Reality, softcover reprint of hardcover 1st ed. 2008 ed. Springer, Dec. 2010.

[15] F. Mas, J. L. Menndez, M. Oliva, A. Gmez, and J. Ros, "Collaborative Engineering Paradigm Applied to the Aerospace Industry," in Product Lifecycle Management for Society, ser. IFIP Advances in Information and Communication Technology, A. Bernard, L. Rivest, and D. Dutta, Eds. Springer Berlin Heidelberg, Jan. 2013, no. 409, pp. 675-684.

[16] F. Mas, J. L. Menndez, M. Oliva, and J. Ros, "Collaborative Engineering: An Airbus Case Study," Procedia Engineering, vol. 63, pp. 336-345, 2013.

[17] J. L. Menndez, F. Mas, J. Servn, and J. Ros, "Virtual verification of the AIRBUS A400m final assembly line industrialization," in AIP Conference Proceedings, vol. 1431. AIP Publishing, Apr. 2012, pp. 641-648.

[18] I. Ari and N. Muhtaroglu, "Design and implementation of a cloud computing service for finite element analysis," Advances in Engineering Software, vol. 6061, pp. 122-135, Jun. 2013.

[19] S. Ma and L. Tian, "A web service-based multi-disciplinary collaborative simulation platform for complicated product development," The International Journal of Advanced Manufacturing Technology, vol. 73, no. 5-8, pp. 1033-1047, May 2014.

[20] P. Galambos, d. Csap, P. Zentay, I. M. Flp, T. Haidegger, P. Baranyi, and I. J. Rudas, "Design, programming and orchestration of heterogeneous manufacturing systems through VR-powered remote collaboration,"
Robotics and Computer-Integrated Manufacturing, vol. 33, pp. 68-77, Jun. 2015.

[21] P. Galambos, C. Weidig, Pter Zentay, d. Csap, P. Baranyi, J. C. Aurich, B. Hammann, and O. Kreylos, "Future Internet-based Collaboration in Factory Planning," Acta Polytechnica Hungarica, vol. 11, no. 7, 2014.

[22] P. Galambos, C. Weidig, P. Baranyi, J. C. Aurich, B. Hamann, and O. Kreylos, "VirCA NET: A case study for collaboration in shared virtual space," in 2012 IEEE 3rd International Conference on Cognitive Infocommunications (CogInfoCom), Dec. 2012, pp. 273 -277.

[23] S. Choi, K. Jung, and S. Do Noh, "Virtual reality applications in manufacturing industries: Past research, present findings, and future directions," Concurrent Engineering, vol. 23, no. 1, pp. 40-63, 2015.

[24] D. Chen, "A methodology for developing service in virtual manufacturing environment," Annual Reviews in Control, vol. 39, no. 0, pp. 102 117, 2015.

[25] W. Zhu, X. Peng, and M. C. Leu, Engineering Applications of Virtual Reality. John Wiley \& Sons, Inc., 2014.

[26] A. Bicchi, M. A. Peshkin, and J. E. Colgate, "Safety for Physical HumanRobot Interaction," in Springer Handbook of Robotics, B. S. Prof and O. K. Prof, Eds. Springer Berlin Heidelberg, 2008, pp. 1335-1348.

[27] B. S. Dhillon, Robot Reliability and Safety. Springer Science \& Business Media, Dec. 2012

[28] J. Fryman and B. Matthias, "Safety of Industrial Robots: From Conventional to Collaborative Applications," in Robotics; Proceedings of ROBOTIK 2012; 7th German Conference on, May 2012, pp. 1-5.

[29] M. Vasic and A. Billard, "Safety issues in human-robot interactions," in 2013 IEEE International Conference on Robotics and Automation (ICRA), May 2013, pp. 197-204.

[30] S. Haddadin, "Physical Safety in Robotics," in Formal Modeling and Verification of Cyber-Physical Systems, R. Drechsler and U. Khne, Eds. Springer Fachmedien Wiesbaden, 2015, pp. 249-271.

[31] P. Galambos, P. Baranyi, and I. Rudas, "Merged physical and virtual reality in collaborative virtual workspaces: The virca approach," in Industrial Electronics Society, IECON 2014 - 40th Annual Conference of the IEEE, Oct 2014, pp. 2585-2590. 